\title{
Bilateral secondary pulmonary tuberculosis complicated with bilateral chylothorax: a case report
}

\author{
Wendong Qü, Qiao Li", Cheng Chen, Yang Tang, Jiebin Zuo, Yongxiang Song, Gang Xu \\ Department of Thoracic and Cardiovascular Surgery, The Affiliated Hospital of Zunyi Medical University, Zunyi, China \\ \#These authors contributed equally to this work. \\ Correspondence to: Yongxiang Song; Gang Xu. Department of Thoracic Surgery, The Affiliated Hospital of Zunyi Medical University, 149 Dalian \\ Road, Zunyi 563000, China. Email: songtang2004@163.com; xglhl333@163.com.
}

\begin{abstract}
A 26-year-old female was admitted to the emergency department of thoracic surgery complaining of chest tightness, shortness of breath, and a history of bilateral tuberculosis. A chest Computed Tomography (CT) scan showed bilateral pleural effusion. After that, the patient was implanted with bilateral intercostal drainage tubes. Further analysis of the pleural effusion was conducted to confirm the diagnosis of bilateral chylothorax. We initiated conservative treatment consisting of fasting and total parenteral nutrition. After the failure of conservative treatment, the patient underwent ligation of the thoracic duct by rightsided thoracotomy combined with talc slurry. On the first day postoperatively, the right pleural effusion had decreased significantly, while the left pleural effusion had not. Subsequently, talc slurry was injected into the left thoracic drainage tube of the patient. Bilateral pleural effusion was significantly reduced. Re-examination chest X-ray showed the disappearance of pleural effusion, and the patient was discharged good healthy. Chest X-rays were reexamined one month postoperatively, and the patient's lung was well dilated, with no recurrence of pleural effusion. In this case, it was shown that conservative treatment is the first choice for chylothorax. However, if this proves to be ineffective, early surgical treatment should be considered. Early diagnosis and timely surgical intervention are the key factors to improve the prognosis of patients.
\end{abstract}

Keywords: Chylothorax; tuberculosis; pleural fluid; conservative treatment; thoracic duct ligation; case report

Submitted Feb 05, 2021. Accepted for publication Apr 21, 2021.

doi: 10.21037/apm-21-605

View this article at: http://dx.doi.org/10.21037/apm-21-605

\section{Introduction}

Chylous pleural effusion, also known as chylothorax, may be caused by obstruction or injury of the thoracic duct or its branches, leading to the flow of chylous fluid directly or indirectly from the abdominal cavity across the diaphragm and into the thoracic cavity. Common causes include trauma (surgery or chest trauma) and malignant tumors that directly erode, damage, destroy, or compress the thoracic duct, while rare causes include primary lymphatic disease, infection, etc. $(1,2)$. This article analyzes the clinical data of a patient with double pulmonary tuberculosis and bilateral chylothorax who was admitted to our department, and reviews the pathogenesis, clinical manifestations, and treatment of the disease.
We present the following article in accordance with the CARE reporting checklist (available at http://dx.doi. org/10.21037/apm-21-605).

\section{Case presentation}

A 26-year-old female patient was admitted to the hospital for 3 months due to chest tightness and shortness of breath. Prior to this, the patient felt chest tightness and shortness of breath, with symptoms worsening for 3 months. The patient had suffered from secondary pulmonary tuberculosis in both lungs 2 years prior. She was given anti-tuberculosis drugs for one and a half years. After admission, a large amount of bilateral pleural effusion was found by chest CT scan (Figure 1). Routine blood biochemistry of the patient 


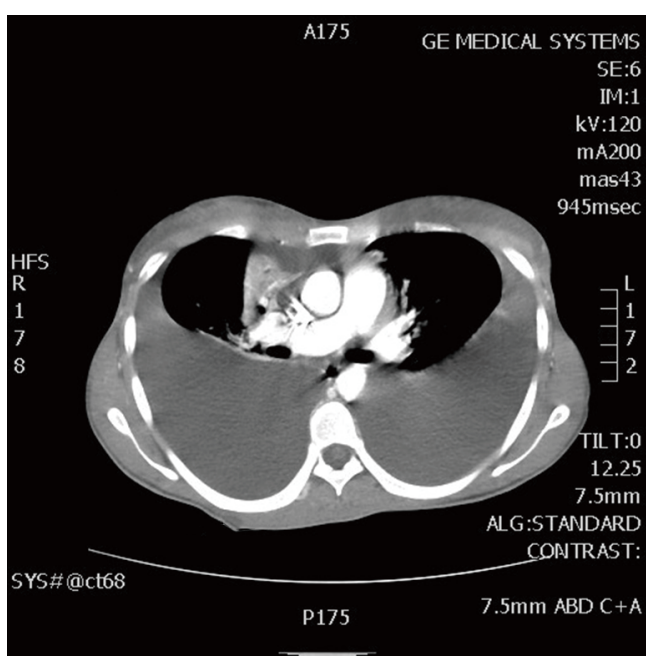

Figure 1 Chest CT images of our patient.

Table 1 Laboratory investigation results of the patient's blood test

\begin{tabular}{lc}
\hline Patients lab tests & Value \\
\hline C-reactive protein $(\mathrm{mg} / \mathrm{L})$ & 14.2 \\
Total protein $(\mathrm{g} / \mathrm{L})$ & 44.6 \\
Albumin $(\mathrm{g} / \mathrm{L})$ & 21.7 \\
Globulin $(\mathrm{g} / \mathrm{L})$ & 22.9 \\
Albumin ratio $(\%)$ & 95 \\
Prealbumin $(\mathrm{mg} / \mathrm{L})$ & 136 \\
HDL-C ${ }^{a}(\mathrm{mmol} / \mathrm{L})$ & 0.63 \\
LDL-C $^{\mathrm{b}}(\mathrm{mmol} / \mathrm{L})$ & 2.26 \\
Apolipoprotein A1 (g/L) & 0.82 \\
Apolipoprotein B $(\mathrm{g} / \mathrm{L})$ & 0.75 \\
Lipoprotein $(\mathrm{mg} / \mathrm{L})$ & 111.29 \\
Blood glucose $(\mathrm{mmol} / \mathrm{L})$ & 3.85 \\
Leukocyte count $\left(\times 10^{9} / \mathrm{L}\right)$ & 7.35 \\
Hemoglobin $(\mathrm{g} / \mathrm{L})$ & 136 \\
cESR (mm/h) & 7 \\
\hline
\end{tabular}

HDL-C, high-density lipoprotein cholesterol; LDL-C, low-density lipoprotein cholesterol; ESR, erythrocyte sedimentation rate.

is shown in Table 1. The patient's body mass index (BMI) was measured to be 13.7 , and the pleural fluid chyle test was determined to be positive (Table 2).

Drainage was performed with bilateral thoracic tubes. A total of 2,300 $\mathrm{mL}$ of light red chylo-like pleural effusion was drained within 24 hours (Figure 2). After receiving
Table 2 Laboratory investigation results of the patient's pleural fluid

\begin{tabular}{lcc} 
& Left & Right \\
\hline Rivalta test & Positive $(++)$ & Positive (+) \\
Chylous test & Positive & Positive \\
Total cell count $\left(\times 10^{6}\right)$ & 117,920 & 141,000 \\
Nucleated cell count $\left(\times 10^{6}\right)$ & 1,230 & 3,100 \\
Neutrophil count $(\%)$ & 70 & 76 \\
Lymphocyte count (\%) & 34 & 30 \\
Fluid glucose (mmol/L) & 6.9 & 7.12 \\
Albumin (g/L) & 19.8 & 23 \\
LDH (U/L) & 89 & 160 \\
ADA (U/L) & 3.52 & 5.10 \\
Cell culture & Negative & Negative \\
\hline LD Iactate dehydrogenase; ADA adenosine deaminase
\end{tabular}

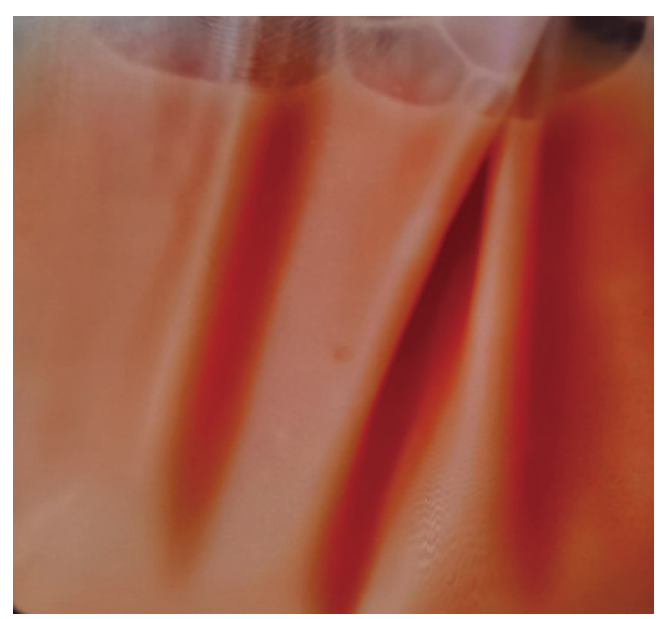

Figure 2 Photo showing the pleural drainage fluid from our patient.

conservative treatments such as fasting and nutritional support, more than $1,500 \mathrm{~mL}$ of chyle pleural fluid was drained within 24 hours. The patient then underwent general anesthesia intubation and lower thoracic duct ligation (see Figure 3). During the operation, $50 \mathrm{~mL}$ of talc slurry was used to fix the pleura. On the first postoperative day, the bilateral thoracic drainage volume of the patient was less than $100 \mathrm{~mL}$. On the second postoperative day, the right thoracic drainage volume was still less than $100 \mathrm{~mL}$, however the left thoracic drainage volume was greater than $500 \mathrm{~mL}$ of light clear fluid; $50 \mathrm{~mL}$ of talc slurry was immediately injected into the left chest tube, and the left thoracic pleura was fixed. On the third day postoperatively, 


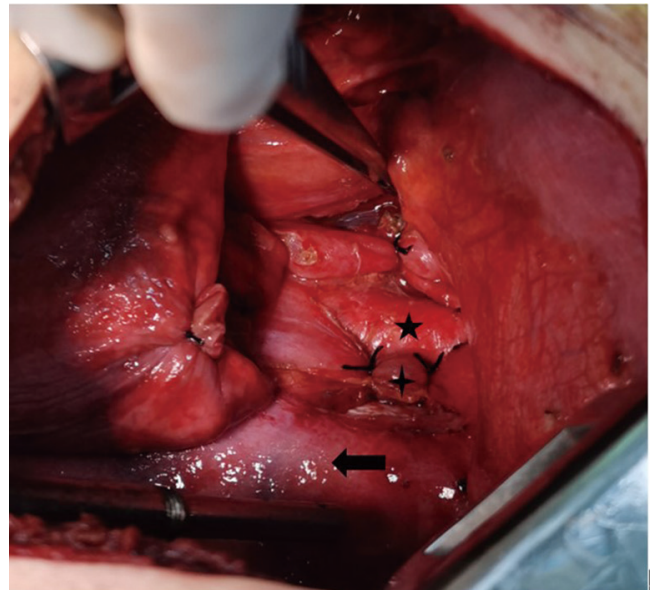

Figure 3 Intraoperative photo. Arrow, spine; star, thoracic aorta; cross, ligated thoracic duct tissue. the left thoracic drainage decreased (Figure 4). Figure 5 shows the results of a plain chest radiograph on the third day after surgery. After discharge, the patient returned to the hospital for re-examination one month and 11 months after operation, as shown in Figures 6,7. During the follow-up, the patient did not complain of any adverse reactions.

All procedures performed in studies involving human participants were in accordance with the ethical standards of the institutional and/or national research committee(s) and with the Helsinki Declaration (as revised in 2013). Written informed consent was obtained from the patient.

\section{Discussion}

Patients with chylothorax are common, with approximately

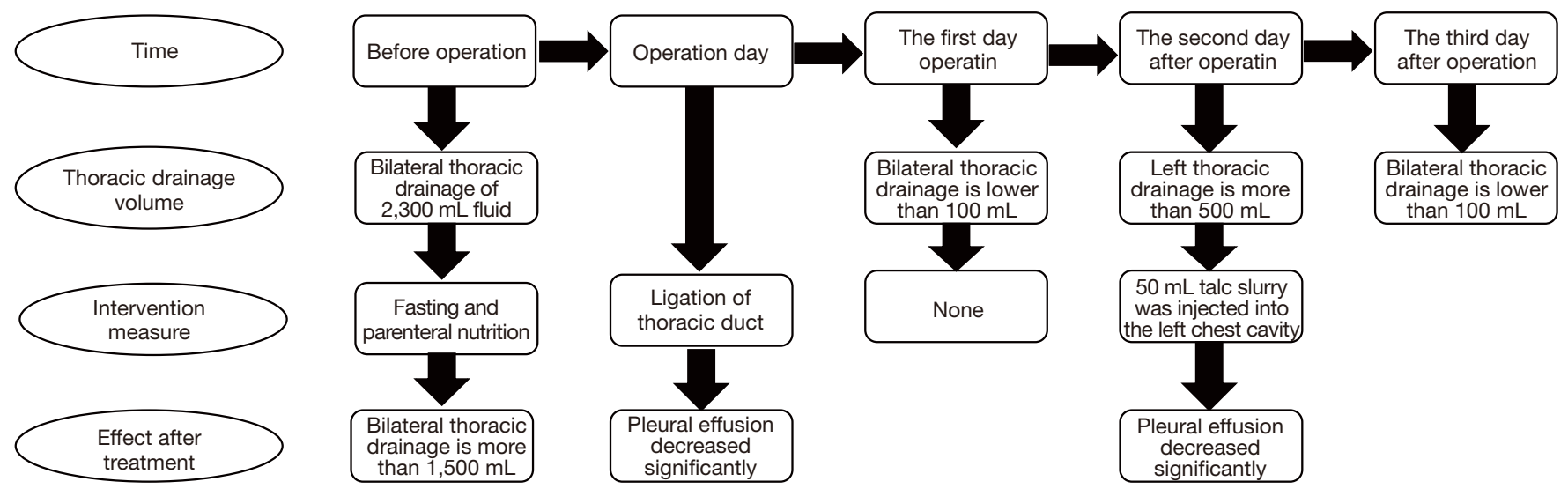

Figure 4 The course of diagnosis and treatment.

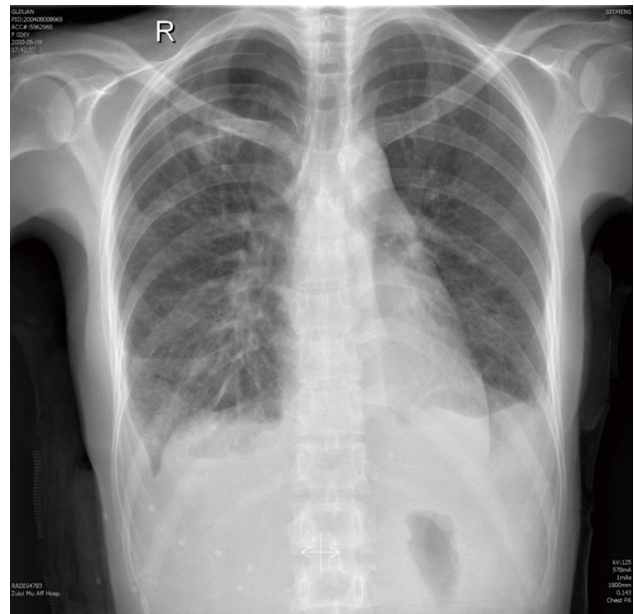

Figure 5 The chest X-ray images of the patient were reexamined on the third day postoperatively.

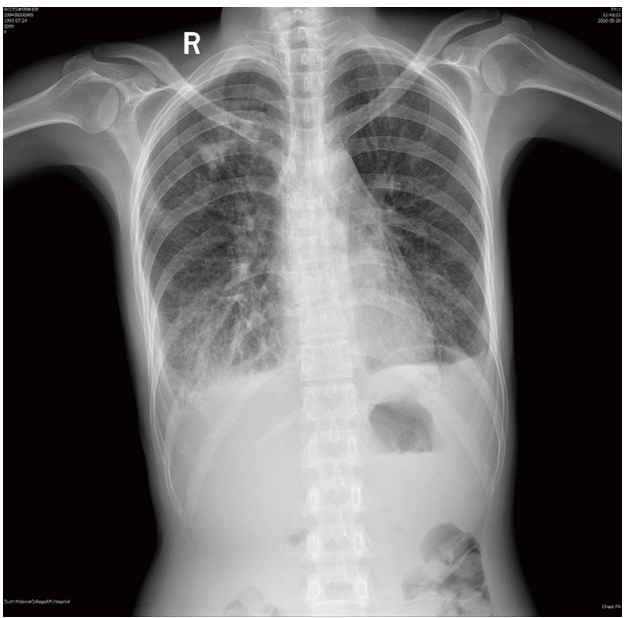

Figure 6 One month after the operation, the chest X-ray was reexamined. 


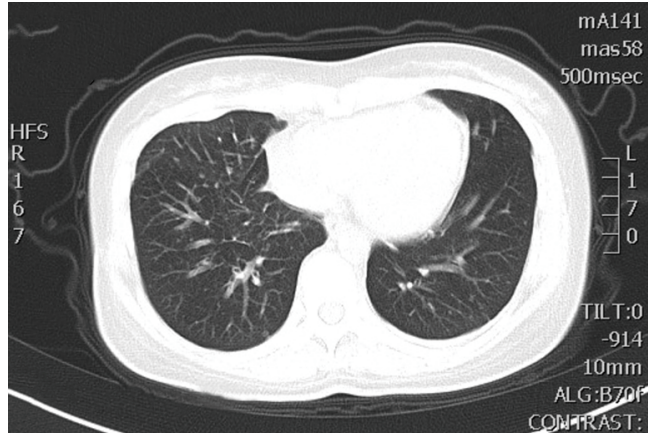

Figure 711 months after the operation, the chest CT was reexamined.

1 in 6,000 patients being hospitalized (3). Chylothorax is divided into traumatic chylothorax and non-traumatic chylothorax (4). Most cases of traumatic chylothorax are caused by damage to the thoracic duct and/or main lymphatic ducts after esophageal surgery (5), while nontraumatic chylothorax is mainly caused by malignant tumors, lymphatic diseases, and infections (1). VENNERA was the first reported a case of tuberculosis infection with chylothorax in 1983 (6). In the case report of Rajagopala, 37 patients with tuberculosis complicated with chylothorax were summarized, of which 35 patients received treatment, with the exception of two deaths, the rest of the patients had a good prognosis. Of the 35 patients who received treatment, only 6 received thoracic duct ligation, which may indicate that conservative treatment is the first choice when conservative treatment can control the disease. On the other hand, we believe that when conservative treatment can not control the disease, surgical intervention should be carried out as soon as possible (7). Chylothorax treatment guidelines suggest that regardless of whether chylothorax has a clear cause, the conservative treatment method should be applied initially, which usually consists of complete fasting, closed chest drainage, use of somatostatin octreotide, a non-fat diet, and complete parenteral nutrition (8). At present, there is controversy in the published literature about when the treatment should be changed from conservative to invasive treatment. Most authors tend to change the treatment after the following situations: (I) conservative treatment proves ineffective after 2 weeks; (II) the closed thoracic drainage is more than $1 \mathrm{~L}$ per day and lasts for more than 5 days; and (III) the drainage volume is more than $1.5 \mathrm{~L}$ within 1 day after the best conservative treatment $(1,9,10)$.

Invasive therapy currently includes interventional therapy and surgical treatment. Interventional therapy involves different approaches to embolize the thoracic catheter (11), while surgical treatment is performed by direct ligation of the thoracic duct through thoracotomy or video-assisted thoracoscopy $(10,12)$. If surgical treatment is ineffective, early reoperation may put the anastomosis at risk, and thus, long-term conservative treatment is recommended. At that time, postoperative pleural fixation has become a safe and effective option (13). Bhatnagar et al. confirmed that regular use of talc can significantly increase the rate of pleural fixation through a randomized controlled trial involving 154 patients with malignant pleural effusion and closed pleural drainage, with patients separated into talc powder and placebo groups (14).

In our case, CT scans only revealed a large amount of pleural effusion, but there was no obvious lung disease. We believe that the chylothorax may have been caused by direct damage to the thoracic duct or major lymphatic channels by conjugated bacilli, however this hypothesis can only be confirmed by postoperative pathological evidence.

\section{Acknowledgments}

Funding: This research was supported by the National Natural Science Foundation of China (grant number 81960532).

\section{Footnote}

Reporting Checklist: The authors have completed the CARE reporting checklist. Available at http://dx.doi.org/10.21037/ apm-21-605

Conflicts of Interest: All authors have completed the ICMJE uniform disclosure form (available at http://dx.doi. org/10.21037/apm-21-605). The authors have no conflicts of interest to declare.

Ethical Statement: The authors are accountable for all aspects of the work in ensuring that questions related to the accuracy or integrity of any part of the work are appropriately investigated and resolved. All procedures performed in studies involving human participants were in accordance with the ethical standards of the institutional and/or national research committee(s) and with the Helsinki Declaration (as revised in 2013). Written informed consent was obtained from the patients.

Open Access Statement: This is an Open Access article 
distributed in accordance with the Creative Commons Attribution-NonCommercial-NoDerivs 4.0 International License (CC BY-NC-ND 4.0), which permits the noncommercial replication and distribution of the article with the strict proviso that no changes or edits are made and the original work is properly cited (including links to both the formal publication through the relevant DOI and the license). See: https://creativecommons.org/licenses/by-nc-nd/4.0/.

\section{References}

1. Riley LE, Ataya A. Clinical approach and review of causes of a chylothorax. Respir Med 2019;157:7-13.

2. Merrigan BA, Winter DC, O'Sullivan GC. Chylothorax. Br J Surg 1997;84:15-20.

3. Doerr CH, Allen MS, Nichols FC 3rd, et al. Etiology of chylothorax in 203 patients. Mayo Clin Proc 2005;80:867-70.

4. McGrath EE, Blades Z, Anderson PB. Chylothorax: aetiology, diagnosis and therapeutic options. Respir Med 2010;104:1-8.

5. Pillay TG, Singh B. A review of traumatic chylothorax. Injury 2016;47:545-550.

6. Vennera MC, Moreno R, Cot J, et al. Chylothorax and tuberculosis. Thorax 1983;38:694-5.

7. Rajagopala S, Kancherla R, Ramanathan RP. Tuberculosis-
Associated Chylothorax: Case Report and Systematic Review of the Literature. Respiration 2018;95:260-8.

8. Expert Panel on Vascular Imaging and Interventional Radiology:, Majdalany BS, Murrey DA Jr, et al. ACR Appropriateness Criteria ${ }^{\circledR}$ Chylothorax Treatment Planning. J Am Coll Radiol 2017;14:S118-26.

9. Akpinar V, Duran FY, Duman E, et al. Bilateral chylhotorax after falling from height. Case Rep Surg 2014;2014:618708.

10. Schirren M, Sponholz S, Schirren J. Treatment of chylothorax. Chirurg 2018;89:563-74.

11. Novelli PM, Chan EG, Frazier AA, Villa Sanchez M. Interventional Therapies for Thoracic Duct Injury and Intractable Chylothorax. J Thorac Imaging 2019;34:258-65.

12. Schild HH, Strassburg CP, Welz A, et al. Treatment options in patients with chylothorax. Dtsch Arztebl Int 2013;110:819-26.

13. Lai $Y$, Zheng $X$, Yuan $Y$, et al. A modified pleurodesis in treating postoperative chylothorax. Ann Transl Med 2019;7:549.

14. Bhatnagar R, Keenan EK, Morley AJ, et al. Outpatient Talc Administration by Indwelling Pleural Catheter for Malignant Effusion. N Engl J Med 2018;378:1313-22.

(English Language Editor: A. Kassem)

Cite this article as: Qu W, Li Q, Chen C, Tang Y, Zuo J, Song Y, Xu G. Bilateral secondary pulmonary tuberculosis complicated with bilateral chylothorax: a case report. Ann Palliat Med 2021;10(4):4970-4974. doi: 10.21037/apm-21-605 